\title{
UNIVERSIDADE NA AMÉRICA LATINA: RUMOS DO FINANCIAMENTO
}

\author{
JACQUES VELLOSO \\ Universidade de Brasília
}

\begin{abstract}
RESUMO
Quais são as principais tendências do financiamento da universidade na América Latina? Que modelos seriam apropriados, tendo em vista as funções da instituição? Essas são as principais questões tratadas no artigo. Baseado em tendências ilustrativas, e considerado o cenário econômico da região, o texto inicialmente aborda alternativas quanto ao papel do Estado e contrasta propostas de financiamento do Banco Interamericano de Desenvolvimento - BID-e da Unesco para países em desenvolvimento. Discutindo modelos de destinação de recursos para a universidade, o artigo trata da diversificação das fontes de recursos; dos contratos de gestão e de sua associação com o mercado e com a interferência de governos, à luz da experiência européia; da gestão da universidade como instituição complexa, necessariamente convivendo com estilos acadêmicos e empresariais de administração; da responsabilidade ética pela eficiência e da preservação da autonomia de gestão financeira. A conclusão da análise argúi a favor de um dos modelos discutidos, envolvendo avaliação institucional, esta entendida como indispensável prestação de contas à sociedade e mediação entre sociedade, Estado e universidade.
\end{abstract}

FINANCIAMENTODAEDUCAÇÃO-UNIVERSIDADES-AVALLAÇÃOINSTITUCIONAL

\section{ABSTRACT}

THE UNIVERSITY IN LATINAMERICA: OPTIONS FOR FINANCING. What are the main trends on university financing in Latin America? Which models would be appropriate, considering the functions of the institution? These are the major questions dealt with in the article. Based on illustrative trends, and considering the economic scenario of the region, the text initially deals with alternatives on the role of the State and sets out contrasts between financing proposals originating from BID and Unesco for developing countries. Discussing resource allocation models, the article addresses the diversification of funding sources; conditional contracting as related to markets and government interference, in the light of the European experience; university management as the administration of a complex institution, in which academic and entrepreneurial approaches necessarily face each other; the ethical responsibility for efficiency and the preservation of autonomy. Concluding the analysis, the text argues in favor of one of the models discussed, which involves institutional evaluation, this being understood as a required ingredient of accountability and as a mediation among society, State and university.

Texto de conferência magistra/na "3a Conferência Internacional do Programa Alfa-Bracara" sobre Asignación de Recursos y Rendición de Cuentas en las Instituciones de Educación Superior, realizada na Unam, cidade do México, de 8 a 10 de fevereiro de 1999. Agradeço a assistência de Sueli Teixeira Mello na preparação e na revisão do trabalho. 
Reformas do financiamento' do ensino superior têm estado na ordem do dia das políticas públicas de países dos quatro continentes. Em alguns, como no Reino Unido, as reformas já foram implementadas e hoje estão em vias de revisão. Noutros estão em pleno desenvolvimento. Em vários países da América Latina há reformas do financiamento em curso, dos mais variados matizes. A origem primeira das reformas remonta aos anos 80 , quando a região passava por grave crise econômica fiscal e, em países anglo-saxões a orientação política de seus governos conduzia políticas neoconservadoras. Na esteira dessas tendências, os anos 80 viram surgir na Europa Ocidental políticas de financiamento que podiam estimular um melhor desempenho de instituições e sistemas o quanto podiam, equivocadamente, reduzir o apoio do Estado ao ensino superior ou atrelar universidades a interesses de governos. Numa ou noutra vertente, políticas como essas têm sido levadas a cabo em nações da América Latina e em países europeus tão diversos quanto a Bélgica, a Inglaterra e a Noruega. $\bigcirc$ caso inglês é notável e merece algumas linhas.

A compressão dos orçamentos das universidades inglesas, deflagrada a partir de 1981, foi levada a cabo por seu órgão de financiamento, o Comitê de Dotações das Universidades $^{2}$, uma instância tida como intermediária entre o Estado e as universidades. A compressão orçamentária, associada à indução de agressiva captação de recursos externos para cobrir os cortes, foi promovida pelas mãos do referido Comitê, preservando-se as aparências quanto à fonte da redução das verbas públicas. Criou-se a notável ficção de que as próprias universidades tomavam as decisões "quanto a enforcarem-se com uma corda de seda ou com uma boa e sólida corda de cânhamo" (Neave, Van Vught, 1991, p.24I-2). $\bigcirc$ caráter fictício da origem dos cortes é reconhecido mesmo por autores favoráveis a políticas de redução da dependência das universidades em relação ao Estado, como Salmi (1992); este observa que a experiência inglesa é uma viva ilustração do papel de bodes expiatórios que, em tempos de cortes de verbas, podem assumir os organismos intermediários (buffer) entre o Estado e as universidades.

Este texto trata do financiamento ao ensino superior na América Latina. Está dividido em cinco seções, além desta introdução. Na primeira seção discutem-se em breves linhas o cenário econômico da região e a economia política do financiamento. Na segunda seção abordam-se propostas que vêm sendo apresentadas por agências multilaterais para o financiamento do ensino superior em países em desenvolvimento. Na terceira são tratados modelos de financiamento, com ilustrações de algumas tendências observadas em alguns países da região. A quarta é dedicada a fontes alternativas de recursos, com ênfase nas relações entre universidade e setor produtivo. Na última seção discutem-se deficiências de três modelos de financiamento, argüindo a favor de um deles, consideradas a autonomia universitária, a avaliação e a prestação de contas à sociedade.

1. Partes deste texto baseiam-se em trabalho anterior sobre a temática semelhante (Velloso, 1997a).

2. University Grants Committee, substituído em 1988 pelo Conselho de Financiamento das Universidades (University Funding Council). 


\section{A ECONOMIA NA AMÉRICA LATINA E A ECONOMIA POLÍTICA DO FINANCIAMENTO}

Durante os anos 80 a América Latina viveu uma grave crise em suas economias, talvez a mais séria desde os anos 30. Na região predominaram tendências econômicas descendentes sobre as de crescimento econômico real, as primeiras freqüentemente acompanhadas de elevadas taxas de inflação. A esse quadro acrescia-se o aumento da dívida externa na América Latina, a sub-região relativamente mais endividada no mundo. Nesse cenário prosperaram políticas de cortes no gasto público e de ajustes estruturais, freqüentemente vinculadas a empréstimos de agências internacionais (Carnoy, Torres, 1992).

Como resultado dessas políticas e da crise fiscal, entre 1980 e 1985 o gasto público real em educação na América Latina caiu 30\%. A recuperação parcial nos anos seguintes fez com que ao final da década o gasto per capita ainda fosse menor do que no seu início e, ademais, ainda fosse equivalente apenas a cerca de um décimo dos padrões observados em países industrializados (Puryear, Brunner, 1995). Nos anos 90 o cenário começou a se alterar. Durante o primeiro qüinqüênio (1990-94) vários países conseguiram conciliar crescimento econômico e redução das taxas de inflação. Alguns dos países que mais cresceram, no entanto, apenas lograram recuperar os níveis perdidos durante a crise dos anos 80 .

As despesas públicas com o ensino superior não ficaram imunes aos largos cortes de gastos públicos efetuados nos anos 80 . Os dados do quadro I são ilustrativos da tendência.

Entre os países incluídos no quadro I apenas a Colômbia apresentava gastos públicos no ensino superior em nível relativo maior do que no início da década. O caso do Chile é especial pois o país adotou vigorosa política de retração do Estado no financiamento do

\section{QUADRO I}

EVOLUÇÃO DOS GASTOS PÚBLICOS NO ENSINO SUPERIOR EM RELAÇÃO AO PIB PAÍSES SELECIONADOS (EM \%)

\begin{tabular}{|lcccc|}
\hline Países / & 1980 & 1985 & 1990 & 1993 \\
Período & & & & \\
Argentina & 0,52 & 0,45 & 0,49 & 0,60 \\
Brasil & 0,68 & 0,67 & 0,42 & $0,54 *$ \\
Chile & 1,45 & 0,89 & 0,56 & 0,56 \\
Colômbia & 0,43 & 0,64 & 0,58 & 0,59 \\
México & 0,68 & 0,48 & 0,42 & 0,57 \\
Venezuela & 1,45 & 1,41 & 1,04 & - \\
\hline
\end{tabular}

Fonte: Barriga et al. (1997, p. 684-9|).

Nota: * Estimativa de Negri (1997, Tab. 7) para 1995. 
ensino superior, embora tenha tido crescimento médio positivo do PIB e do PIB por habitante durante os anos 80. Nos anos iniciais da década de 90, em torno de 1993, os gastos públicos no ensino superior como porcentagem do PIB haviam crescido na Argentina e na Colômbia, por exemplo, mas apresentavam-se abaixo do nível de 1980 no Brasil e no México.

Em 1996, segundo estimava a Comissão Econômica para a América Latina e Caribe Cepal -, havia sinais de que a região superava o estancamento do ano anterior, apresentando moderadas perspectivas de crescimento para a década. No ano seguinte os resultados foram mais alentadores do que as estimativas. Mas a crise financeira que começou na Ásia em 1997, e que esteve prestes a desencadear uma catástrofe de grandes proporções, revelou que mesmo após os ajustes estruturais anteriormente realizados permaneciam as economias com marcada vulnerabilidade externa ${ }^{3}$. Considerada a magnitude dos choques, as economias da região tiveram um desempenho razoável em 1998; um crescimento médio do PIB de 5,2\% em 1997 caiu para cerca 2,3\% no ano seguinte (Quadro 2).

QUADRO 2

EVOLUÇÃO DO PIB TOTAL E POR HABITANTE PAÍSES SELECIONADOS DA AMÉRICA LATINA (EM \%)

\begin{tabular}{|lcccccc|}
\hline Países / & \multicolumn{2}{c}{$|98|-1990$} & \multicolumn{2}{c}{$|99|-1998$} & 1997 & I998 \\
Período & PIB & PIB/hab. & PIB & PIB/hab. & PIB & PIB \\
Argentina & $-0,7$ & $-2,1$ & 5,2 & 4,4 & 8,4 & 4,0 \\
Brasil & 1,3 & $-0,7$ & 2,7 & 1,2 & 3,0 & 0,5 \\
Chile & 3,0 & 1,3 & 6,9 & 5,7 & 7,1 & 4,0 \\
Colômbia & 3,7 & 1,6 & 3,3 & 0,7 & 3,0 & 2,0 \\
Equador & 1,7 & $-0,9$ & 2,9 & 0,8 & 3,3 & 1,0 \\
México & 1,8 & $-0,3$ & 2,5 & 1,3 & 7,0 & 4,5 \\
Paraguai & 3,0 & 0,0 & 2,4 & $-0,3$ & 2,6 & 0,0 \\
Peru & $-1,2$ & $-3,3$ & 5,3 & 3,6 & 7,4 & 1,0 \\
Uruguai & 0,0 & $-0,6$ & 3,3 & 2,9 & 5,1 & 2,5 \\
Venezuela & $-0,7$ & $-3,2$ & 2,3 & 0,0 & 5,1 & $-1,0$ \\
Média A.L.* & 1,0 & $-1,0$ & 3,3 & 1,7 & 5,2 & 2,3 \\
\hline
\end{tabular}

Fonte: Cepal (1999, p. I).

Nota: * Média de 19 países.

3. Em janeiro de 1999 os reflexos da crise invadiram o Brasil que, entre outras medidas, se viu forçado a desvalorizar a moeda em relação ao dólar norte-americano. 
Como muitos dos choques têm conseqüências que se manifestam num prazo mais longo do que sua visibilidade imediata, as perspectivas para 1999 continuam sendo delicadas (Cepal, 1999, p.I-2). O padrão médio registrado para a região foi observado em vários países, como na Argentina e no Uruguai, cujo crescimento anual do PIB caiu para mais da metade; quedas muito maiores foram registradas no Brasil, no Equador, no Paraguai e na Venezuela.

Aquelas políticas econômicas de ajuste adotadas em muitos países da região respondiam ao abandono dos modelos keynesianos centrados na demanda e no desenvolvimento. Estes foram substituídos por preocupações com a estabilidade monetária, a eficiência produtiva e o alargamento do papel do mercado (Narodowsky, 1995), às quais se somavam a modernização do Estado, a redução de seu tamanho e de seus papéis.

Nos início dos anos 90, no debate das bases conceituais e estratégicas das políticas econômicas e dos papéis do Estado, configuravam-se novas perspectivas. Estas eram diversas das que presidiram à maioria dos ajustes estruturais mencionados, e cuja orientação freqüentemente baseava-se no que veio a ser conhecido como o consenso de Washington. Nessas novas perspectivas, que alguns denominaram novo consenso, reconhecia-se a importância e o caráter inadiável da austeridade monetária e fiscal que integrava as chamadas políticas de ajuste macroeconômico. Reconhecia-se também a necessidade inadiável de modernizar o Estado, de reformá-lo, retirando-o de áreas de atuação na economia nas quais o setor privado poderia ter maior êxito a menores custos.

Apesar dessas coincidências com as propostas ortodoxas das políticas de ajuste macroeconômico, eram e são grandes as diferenças entre uma e outra perspectiva. Primeiro, porque na nova perspectiva o êxito das políticas econômicas de ajuste ou das políticas sociais não residiria em soluções tecnocráticas, mas na articulação de um projeto nacional que contasse com o apoio de uma sólida coalizão política e apoio empresarial. Segundo, porque a peça-chave de uma nova política de desenvolvimento econômico e social continuaria sendo o Estado, forte sem ser autoritário, coordenador de expectativas, mas desvinculado de seu papel como agente econômico. Não se trataria de desmontar ou de "minimizar" o Estado em crise, mas de reconstruí-lo, moderno, ágil e flexível. Terceiro, porque a democracia seria assumida como um objetivo ético-político que além de ser valioso em si mesmo seria o caminho para uma harmoniosa reestruturação do Estado e de um crescimento mais equânime. Quarto, porque instrumentos modernos de política econômica e social teriam seus resultados submetidos a rigorosos mecanismos de avaliação e controle. Tratar-se-ia de regenerar a burocracia estatal mediante o estabelecimento de um sistema meritocrático, transparente e flexível, imune a influências clientelistas (Fiori, 1993).

O teor das novas bases conceituais e estratégicas das políticas econômicas e sociais, no que se refere ao papel do Estado na economia e na sociedade, além de seu interesse intrínseco, tem dois tipos de implicações para os objetivos deste texto, pois sugere diretrizes para a discussão de modelos de financiamento do ensino superior. 
A primeira implicação diz respeito à natureza política da introdução de mudanças ou reformas - quanto ao financiamento das universidades. Do mesmo modo que o êxito de novas políticas econômicas depende da articulação de um projeto nacional apoiado em sólida coalizão política e apoio empresarial, a introdução de reformas no financiamento da universidade depende da consecução de pactos entre o Estado - nele incluídos os partidos políticos -, a comunidade acadêmica e os demais setores sociais interessados. A segunda implicação refere-se ao papel do Estado no financiamento da universidade. Se naquelas novas bases conceituais e estratégicas cabe ao Estado um novo e fortalecido papel na coordenação das expectativas e no desenvolvimento econômico e social, a ele também deve caber robustecida presença na condução das políticas educacionais e no financiamento da educação, em especial no financiamento das universidades públicas.

\section{PROPOSTAS DE AGÊNCIAS MULTILATERAIS PARA PAÍSES EM DESENVOLVIMENTO}

Na América Latina, com maior ou menor intensidade neste ou naquele país, o ensino superior passou por notável expansão nos anos 70 e 80, acompanhando tendências já registradas ou em manifestação nos países industrializados. Apesar desse crescimento, as taxas de matrícula na faixa etária geralmente são baixas se comparadas, por exemplo, às de países recém-industrializados da Ásia. Pode-se dizer que, de um modo geral, há, na região, uma legítima e crescente demanda por vagas, de resto necessárias para que esse nível de ensino possa aportar a contribuição que the cabe no desenvolvimento social e econômico de cada país.

As principais agências multilaterais para o financiamento do ensino superior na região, entretanto, têm oferecido propostas que vão em sentido oposto àquela legítima demanda e àquela necessária contribuição das universidades para o desenvolvimento. Como notam Easton e Klees (1990), durante os anos 70, problemas relativos à equidade e eficácia dos sistemas de ensino freqüentemente constavam da agenda das políticas educacionais. As soluções aventadas para enfrentá-los geralmente referiam-se à ampliação do papel do Estado na melhoria e expansão do ensino oferecido e na obtenção de recursos públicos adicionais para tanto.

Durante os anos 80, persistindo os mesmos problemas, a literatura registrava propostas para melhorar a equidade, a eficácia e a melhoria do desempenho do ensino superior. Entretanto, como indicam os autores, agências internacionais passaram a propor abordagens totalmente diversas para fazer face aos mesmos problemas. Acompanhando o desenvolvimento de políticas neoconservadoras (ou neoliberais, como foram denominadas na América Latina) em alguns países industrializados, vieram à luz, intensamente, propostas de redução de recursos fiscais para o setor educacional. Assim, instituições como o Banco Mundial passaram a recomendar que países em desenvolvimento enfrentassem pro- 
blemas de eqüidade e desempenho em seus sistemas de ensino mediante a cobrança de "taxas de usuários" e a crescente participação de recursos privados em seu financiamento. Tais recomendações, tendo especial relevância para o ensino superior da região - que no setor público habitualmente ofereciam ensino gratuito -, insistiam na busca de fontes de financiamento alternativas aos recursos provindos do Estado (World Bank, 1994). Nos últimos anos as recomendações originais sofreram qualificações, embora seu eixo central não tenha sido alterado.

Recente documento do Banco Interamericano para o Desenvolvimento - BID aponta em direção parecida, porém com várias qualificações ${ }^{4}$. Correndo o risco de simplificações em virtude do espaço aqui dedicado à discussão do documento, cabe registrar que a crença num quase-mercado no qual competem as instituições mais capazes é o ponto de partida das recomendações e das condições para obtenção de empréstimos do banco.

As instituições privadas teriam surgido onde as públicas não produziram mudanças suficientes. Nos termos do documento, embora muitas particulares recentemente criadas "exibam profundas debilidades, a maior parte delas apresentam aquilo que a agenda da modernização requer: diferenciação institucional, financiamento privado, enormes melhorias nas medidas padrão de eficiência e limitado conflito político". Além disso, continua o documento, as instituições privadas de elite do setor católico e não confessional geralmente

...ostentam uma importância acadêmica, econômica e política que transcende sua parcela nas matrículas do conjunto. As instituições privadas adaptam-se a ambientes em mutação e fazem muito do que as vagarosas universidades públicas nunca fizeram ou há tempos já não fazem bem. (BID, 1998, p. 4-5)

As particulares "vivem em mercados competitivos, auferem suas próprias receitas e governam-se a si próprias". Tal diagnóstico, reconhecendo marcantes debilidades nas novas instituições privadas, encontra virtudes de liderança nas universidades deste setor que acolhem elites e qualidades de competitividade e eficiência nas particulares em geral, apostando em seu potencial para atender ao modelo tido como adequado pelo BID.

O documento apóia uma crescente "recuperação de custos", que pode incluir cobrança de anuidades (com empréstimos) nas instituições públicas ou um aumento da participação da matrícula no setor privado; apóia também uma redução nos recursos públicos destinados ao ensino superior como porcentagem dos custos totais. O cenário desejável é aquele no qual as verbas do Estado vão cedendo lugar a uma combinação de financiamento privado e público.

Os argumentos para essas recomendações, tal como se apresentam, são de fundo

4 Documento elaborado por C.M. Castro e D. Levy, com a assistência de A. Bernasconi, disponível na Internet no site da Sociedade Brasileira para o Progresso da Ciência - SBPC. A data da referência bibliográfica é a da apropriação na Internet. 
social e econômico. Os subsídios públicos ao ensino superior significariam que os mais pobres que não têm acesso a este nível de ensino custeariam indiretamente os mais privilegiados; salários relativamente mais elevados (isto é, taxas de retorno positivas para maiores gastos dos indivíduos com mais escolaridade) consistiriam em adequados incentivos para os investimentos das pessoas e, portanto, em estímulos para que elas seguissem um curso superior pago. Os argumentos em seguida são qualificados. Quanto à recuperação de custos, o documento refere-se aos efeitos das imperfeições dos mercados e à presença de externalidades que não se refletem nos salários. Quanto aos diferenciais de acesso à universidade por nível social, aponta que eles resultam sobretudo de debilidades nos níveis educacionais anteriores e não de políticas de financiamento à educação. Por fim, advertem quanto à oportunidade política da adoção das medidas que propõem. Assim, mesmo que a eqüidade e a eficiência indiquem que é desejável a adoção de políticas de recuperação de custos, afirma o documento que os conflitos decorrentes de uma imposição inoportuna poderiam anular os benefícios delas decorrentes (p. 16-18).

As qualificações, no entanto, não impediram que as recomendações originais fossem mantidas. A simpatia manifestada pelo BID com instituições particulares, as quais potencialmente atuariam como ponta de lança de um desejável futuro para o ensino superior, parece não dispor de evidência empírica que possa sustentá-la com firmeza. As rápidas respostas que as instituições privadas dariam a ambientes em mudança, por exemplo, um dos motivos para que venham a ser privilegiadas, podem atender mais a seus objetivos próprios do que a necessidades do país. Além disso, Tilak (|99|) indica que, na maior parte dos países em desenvolvimento, o ensino superior privado oferece principalmente cursos que são intensivos em mão-de-obra; no Peru, na Colômbia e no Equador, por exemplo, uma desprezível fração desse ensino oferece cursos em Medicina e na área de Ciências Exatas. A evidência disponível quanto à eficiência interna destas instituiçõos, embora parca, tampouco sugere que elas alcancem níveis desejáveis, segundo resultados coligidos pelo autor: as taxas de evasão no ensino superior são maiores no setor privado do que no setor público na Tailândia e nas Filipinas, por exemplo, países com grande proporção da matrícula no ensino particular; as taxas de insucesso também são mais elevadas no setor particular na Indonésia e na Colômbia.

O documento do BID também recomenda que o financiamento público seja baseado em avaliações do desempenho e que os recursos sejam concedidos sob a forma de montantes globais (/ump-sum ou block grants), em vez de repassados mediante orçamentos com categorias de despesas que são virtualmente inalteráveis. É acertada a recomendação quanto aos montantes globais, não apenas na ótica da autonomia universitária como também do ponto de vista da eficiência das instituições, como argumenta o documento. As práticas de gestão orçamentária que têm prevalecido na América Latina para as instituições públicas de ensino superior, devido a imposições legais, constituem-se em conhecidas e sérias limitações ao bom desempenho das universidades. 
No plano das recomendações das agências multilaterais, as da Unesco fazem contraponto às do BID e às do Banco Mundial. Em 1995 a Unesco aprovou importante documento sobre o ensino superior (Unesco, 1995), vazado em termos profundamente diversos de seu análogo produzido pelo $\mathrm{BID}^{5}$. Recomenda o documento que tanto a sociedade quanto o Estado precisam ter claro que os gastos nesse nível de ensino constituem um "investimento a longo prazo para aumentar a competitividade econômica, o desenvolvimento social e a coesão social" (Unesco, 1995, p.9); tal concepção é indispensável para que o ensino superior possa cumprir suas funções na região. Acentua ainda, corretamente, que continua "sendo essencial o apoio do Estado ao ensino superior". Essa conceituação do papel do Estado assume importância maior no contexto da América Latina, seja pelas tarefas maiores que a ele cabem no desenvolvimento econômico e social, conforme se discutiu acima, seja porque fontes de financiamento não desprezíveis e tradicionais em países industrializados, como os contratos de pesquisa e as doações, têm reduzido potencial para aportar recursos adicionais ao ensino superior na região.

Muito diversas também são as recomendações quanto às fontes de financiamento.

Ao reafirmar que o apoio público ao ensino superior continua sendo indispensável, o documento ao mesmo tempo reconhece que as "limitações no financiamento com verbas do Estado" vêm produzindo tensões entre a comunidade universitária e o Estado. Diante dessas limitações, entende o documento que diversos atores - as autoridades nacionais, os setores público e privado, alunos, pais, entre outros - devem intervir no processo de busca de "novas fontes de financiamento". O documento, entretanto, certamente considerando a evidência empírica disponível, reconhece as limitações da própria recomendação quando lembra que não se pode esperar que novas fontes venham a "eliminar a crise da educação superior nem frear o processo de deterioração que hoje aflige muitas instituições" (Unesco, op. cit., p.8-9).

Em 1998, outro documento sobre o ensino superior foi aprovado pela Unesco, resultado de sucessivas reuniões regionais que culminaram em evento mundial. Várias das recomendações anteriores se mantiveram, porém houve relevantes inovações sobretudo no que respeita ao papel do Estado no financiamento ao ensino superior.

Talvez em decorrência das novas tendências políticas em vários países da União Européia na segunda metade dos anos 90, quando governos conservadores ou liberais foram substituídos por outros, de orientações sociais democratas, o novo documento concede destaque ainda maior ao papel do Estado e não recomenda a busca de fontes de financiamento alternativas aos recursos públicos. As prescrições da Unesco consistem, em larga medida, num contraponto, justificado, e numa resposta às propostas do BID quanto à redução do papel do Estado no financiamento do ensino superior.

No novo documento, o "financiamento da educação superior requer recursos

5. Para uma comparação do documento com o do Banco Mundial sobre o ensino superior, ver Kent (1995). 
públicos e privados. O Estado mantém seu papel essencial neste financiamento". No correto entendimento da Unesco, o financiamento público é reflexo do apoio que a sociedade empresta ao nível superior, "e deve, portanto, continuar a ser reforçado a fim de garantir o desenvolvimento" da educação neste nível, para que ela possa elevar sua "eficácia" e preservar sua "qualidade e relevância". Para tanto, o documento faz um apelo para que sociedade em seu conjunto apóie "a educação em todos os níveis, inclusive o superior, dado seu papel na promoção do desenvolvimento econômico, social e cultural sustentável" (Unesco, 1998, p. 32).

Há ainda outras inovações de relevo no documento de 1998. Uma delas é a que se refere à autonomia de gestão das instituições de ensino superior. Outra é a ênfase maior na accountability (prestação de contas à sociedade) e na avaliação, certamente reflexo do aumento do espaço concedido a estas questões na agenda das políticas públicas de vários países e na literatura. Assim, afirma o documento que em suas atividades acadêmicas devem as instituições de ensino superior desfrutar de liberdade e de autonomia plenas. Essas consistem num conjunto de direitos e obrigações, incluindo-se o dever de prestar contas à sociedade. Assim, à autonomia de gestão deve corresponder "a responsabilidade clara e transparente perante o governo, parlamentos, estudantes e a sociedade em geral". O conceito de relevância do ensino superior, já tratado no documento anterior, é retomado na ótica da avaliação: a relevância do ensino superior deve ser avaliada em termos do ajuste entre o que a sociedade espera das instituiçõos e o que estas realizam. A avaliação, entretanto, deve ter escopo muito mais amplo do que a apreciação da relevância, abrangendo o conjunto das atividades das instituiç̧̃̃es, compreendendo "uma auto-avaliação interna transparente e uma revisão externa com especialistas independentes, se possível com reconhecimento internacional". Tais processos de avaliação devem considerar os "contextos institucionais, nacionais e regionais específicos", evitando uma indesejável padronização que produza resultados distantes de seus contextos (Unesco, op.cit., p.|8, 22, 28, 31).

\section{MODELOS DE FINANCIAMENTO E ALGUMAS TENDÊNCIAS NA AMÉRICA LATINA}

As formas de destinação de recursos públicos ao ensino superior podem ser agrupadas em duas categorias: financiamento básico (core funding) e suplementar. Interessa a primeira categoria que pode ser, grosso modo, conceitualmente subdividida em quatro modelos: incremental ou inercial, fórmulas, contratos de gestão e subsídios a alunos (Organização para Cooperação e Desenvolvimento Econômico - OCDE, 1990).

Na prática, raramente um dos modelos é encontrado em sua forma pura, ou exclusiva, habitualmente convivendo num mesmo país mais de um deles. A vantagem de utilizálos como referência é a que tem todo e qualquer modelo, ou seja, a simplificação de 
complexidades empíricas. Por isso mesmo, não abrangem adequadamente os escopos e os matizes - muitos deles antagônicos entre si - das recomendações das agências multilaterais quanto ao financiamento há pouco tratadas. Mas para os propósitos deste texto, convém valer-se de tais modelos, descrevendo-os sucintamente, a fim de que em seguida possam ser mais bem passadas em breve revista algumas das experiências de países latinoamericanos no que concerne ao financiamento do ensino superior. Posteriormente aquelas recomendações serão retomadas em perspectiva apropriada.

O primeiro modelo de financiamento do ensino superior, denominado incremental ou inercial -, envolve práticas de alocação de verbas segundo o orçamento do ano anterior de cada instituição, geralmente mediante negociações entre universidades e governo, sendo as decisões baseadas em critérios ad hoc que variam segundo o cenário econômico e político. O segundo modelo é o do financiamento por contratos. Neste, orientado pelos objetivos de determinada política pública, definem-se os recursos mediante contratos de gestão firmados entre instituições e governo (por vezes também com o setor privado), tendo em vista o desenvolvimento de atividades e o cumprimento de metas por ele estabelecidas.

O terceiro modelo é o do financiamento público por fórmulas, que podem envolver a combinação de um largo espectro de variáveis, relativas à manutenção da instituição, como o número de docentes e de alunos em cada instituição, até indicadores tidos como de desempenho, como a relação entre a matrícula nova e o quantitativo de diplomados, passando por índices tidos como de eficiência, a exemplo das relações médias aluno/docente, por universidade ou área do conhecimento.

quarto modelo seria o do aporte de subsídios a estudantes. Na verdade, no cenário da América Latina, tal modelo situa-se na categoria de aportes complementares de recursos por parte do Estado, dado que o ensino público na região é financiado por verbas públicas, com raras exceções. Nesse modelo, as anuidades a serem pagas pelos estudantes podem ser objeto de empréstimos subsidiados por parte do Estado, sendo a dívida resgatada em alguns anos após a graduação.

Na América Latina ainda domina o modelo de financiamento inercial e negociado. Mas a virtual exclusividade desse formato de alocação de verbas públicas no passado recente vem perdendo terreno para outros modelos. Como assinalou Durham (1998, p. 102), nas novas propostas alteram-se as relações entre ensino superior público e Estado, substituindo-se um sistema de controles governamentais centralizado e burocrático, com financiamento incremental - ou inercial -, "por um outro, baseado na contenção da expansão dos gastos públicos, na descentralização administrativa e na introdução de processos de avaliação". Quais as implicações de modelos como esses para a autonomia universitária e para os destinos do ensino superior na região? Antes de iniciar tal discussão vale a pena passar em breve revista alguns casos ilustrativos de modelos de financiamento que estão sendo postos em prática em países da região. 
Argentina

Os anos 90 na Argentina testemunharam um conjunto de reformas que afetaram o financiamento das universidades, incluindo-se o estímulo para que buscassem fontes de recursos alternativas ao Estado. Outras inovações foram a criação de um fundo para a melhoria da qualidade universitária (Fomec), que financia programas de investimento e de formação pós-graduada, e a de uma comissão de avaliação e credenciamento universitário (Marquis, 1996).

modelo de alocação de recursos públicos a universidades para financiamento básico (core funding) vinha sendo inercial, com negociações baseadas em orçamentos anteriores. Duas recentes e importantes inovações consistiram (i) no repasse de montantes globais (block grants), de livre utilização pelas instituições, e (ii) no uso de fórmulas. A primeira ensejou aumento da autonomia universitária, embora de fato em grau reduzido pois uma grande parcela dos orçamentos é com gastos de pessoal. A segunda, iniciada em 1997, nesse ano incidiu sobre apenas I,3\% dos recursos (Fanelli, 1997). A fórmula empregada baseia-se em custos médios de instituições diversas e nela estão embutidas diretrizes quanto ao aumento da relação concluintes/novos alunos e do número de disciplinas cursadas pelos estudantes, assim como limitações para a ampliação da matrícula em certas carreiras.

A legislação anterior, que assegurava a gratuidade do ensino superior público, foi alterada para permitir a instituição de anuidades nas universidades públicas e os cursos de pós-graduação passaram a cobrá-las. Atualmente a maioria da pós-graduação sustenta-se com receitas próprias. A diversificação das fontes de financiamento resultou em receitas próprias da ordem de 10\% dos recursos totais das universidades públicas argentinas (segundo estimativa da autora).

No começo da década iniciou-se a adoção de uma política de descentralização dos salários dos docentes. Devido à complexidade de sua execução - basta lembrar que apenas a Universidade de Buenos Aires tem cerca de 22 mil professores -, a política teve plena implementação apenas nas novas universidades públicas criadas nos anos 90 na região da Grande Buenos Aires. Em meados da década foi implantado um programa de incentivos a docentes pesquisadores, concedendo aumentos aos que ensinam e fazem pesquisa, o que conduziu a diferenciações salariais no setor público que alcançam cerca de $20 \%$ do pessoal docente. $\bigcirc$ programa teve impacto significativo sobretudo entre os professores de dedicação exclusiva, que constituem minoria do pessoal docente no setor.

Brasil

O principal traço distintivo do financiamento da educação brasileira certamente é a vinculação de receitas de impostos, estabelecida pela Constituição Federal. $\bigcirc$ governo 
central deve aplicar no mínimo $18 \%$ e os governos estaduais pelo menos $25 \%$ de suas receitas de impostos no ensino.

No Brasil convivem três modelos de financiamento do setor público, setor esse que abrange $40 \%$ da matrícula total no ensino superior e que, nas avaliações da graduação e dos programas de mestrado e doutorado, geralmente tem revelado melhor qualidade do que o setor privado. Há um modelo para as instituições federais, mantidas pelo governo central, outro para as universidades mantidas pelo Estado de São Paulo e outro para as demais. Nas universidades federais, os recursos que não se referem a pessoal são financiados segundo um modelo de fórmula ${ }^{6}$, que substituiu o antigo modelo incremental desde 1994; tais recursos correspondem a uma pequena parcela dos orçamentos, da ordem de $6 \%$ (Canto et al., 1998). A fórmula tem um componente de necessidades e outro de desempenho, este proporcionalmente pequeno, que cresce anualmente. $\bigcirc$ primeiro envolve o orçamento do ano anterior e variáveis como área construída e matrícula por área do conhecimento; o segundo inclui variáveis como relação aluno/docente, número de novos alunos e de diplomados, resultados das avaliações da pós-graduação (conduzidas por agência de fomento) e titulação dos professores (Amaral, 1994).

A gestão financeira das universidades federais padece de rígidas restrições orçamentárias, típicas na América Latina, o que motivou as instituições a criarem fundações privadas para a captação e gestão de receitas próprias. $\bigcirc$ ensino público é gratuito por determinação constitucional e os recursos de fontes alternativas, oriundos sobretudo de prestação de serviços, estão em torno de 5\% dos orçamentos (dados de J. Schwartzman, 1998). Existe um projeto do governo para a autonomia das universidades federais, mediante o qual uma nova figura jurídica lhes concederia autonomia de gestão financeira, inclusive para estabelecer salários dos professores. Os recursos passariam a ser transferidos em montantes globais, oriundos de um fundo que disporia de três quartos dos $18 \%$ de impostos que o governo central precisa aplicar no ensino. O projeto aponta na direção correta, embora duas questões-chave ainda estejam em aberto: a parcela do fundo que caberia às universidades federais e as fontes e mecanismos de um outro fundo, destinado a aposentadorias (Velloso, 1997a). São concedidas bolsas de produtividade a pesquisadores há muitos anos. Na transição para a autonomia, em 1998 foi implantado um programa de diferenciação salarial baseado em horas de aula efetivamente ministradas e em outras variáveis referentes ao desempenho docente.

As universidades mantidas pelo governo estadual de São Paulo dispõem, desde 1989, de recursos vinculados (cerca de 10\%) de um imposto estadual, transferidos em montantes globais, com autonomia para sua aplicação, respeitado o teto para gastos com pessoal. A repartição dos recursos é feita pelo Conselho de Reitores dessas universidades, que têm autonomia para estabelecer suas escalas de salários dos docentes (Magalhães

6. No início da década foi ensaiado um outro modelo de fórmula, o qual não prosperou em virtude do impeachment do então Presidente. Noutra oportunidade discuti esta proposta de modelo (Velloso, 1994). 
Castro, 1995). Para as demais universidades públicas, majoritariamente mantidas pelos governos dos estados, prevalece o modelo de financiamento inercial.

As instituições privadas são mantidas em larga medida pela cobrança de anuidades de seus alunos. Um programa de crédito educativo subsidiado pelo governo central atende a parcela pequena dos estudantes das universidades particulares, mas em algumas instituições os empréstimos chegam a 20\% de suas receitas (Canto et al., op. cit.).

Um sistema de avaliação externa ${ }^{7}$ do ensino de graduação vem sendo implementado gradualmente, mas não está conectado ao financiamento. Já os resultados do tradicional sistema de avaliação dos programas de mestrado e doutorado, implantado há quase duas décadas, têm implicações para o financiamento complementar desses programas e para a distribuição de bolsas de estudo aos estudantes.

Chile

As reformas do ensino superior chileno, sobretudo quanto ao seu financiamento, são as que mais se aproximam das recomendadas por agências como o Banco Mundial e o BID. As universidades "tradicionais" chilenas, que incluíam tanto públicas como particulares, antes das reformas não cobravam anuidades e contavam com financiamento regular do Estado, predominantemente mediante transferências globais de livre emprego pelas instituições ${ }^{8}$. No novo modelo, que decorre de transformações iniciadas nos anos 80, o financiamento básico foi limitado às 8 universidades tradicionais e a 17 novas universidades públicas; continua sendo repassado anualmente e conectado ao orçamento do ano anterior, porém precisa ser complementado por recursos provenientes de fontes diversas (Brunner, 1996).

As principais fontes: são as anuidades cobradas dos alunos; recursos para pesquisa majoritariamente oriundos do governo - obtidos em bases competitivas de projetos e mediante revisão por pares; verbas de desenvolvimento institucional do Ministério da Educação, concedidas em bases competitivas e segundo projetos específicos; receitas de serviços mediante contratos com o setor público e privado; doações privadas que contam com incentivos fiscais; fórmula dos melhores estudantes, mediante a qual uma parcela pequena dos recursos públicos é alocada para instituições nas quais estudam os 27.500 mais bem colocados em teste padronizado de âmbito nacional. Nas universidades que recebem financiamento básico com recursos públicos, os alunos em geral pagam o custo estimado e há empréstimos subsidiados com verbas governamentais para os que comprovem incapacidade de pagamento.

7. Para uma comparação dos sistemas de avaliação no Brasil e Argentina, ver Cunha (1999).

8. Originalmente estas compreendiam duas universidades públicas e seis particulares (três católicas e três não confessionais); posteriormente as faculdades regionais da mais antiga universidade católica deram origem a três novas universidades, que também passaram a contar com financiamento do Estado. 
financiamento público assenta-se em fórmula integrada por quatro variáveis: um montante global baseado no orçamento anterior, como acima referido; uma quantia baseada no número de estudantes novos; outra parcela que depende do número de alunos que satisfaçam a certos requisitos acadêmicos e uma outra já referida, a fórmula dos melhores estudantes (Sanyal, Martín, 1997).

As novas políticas do ensino superior, como informa Brunner (op. cit.), orientam-se pelo mercado, assentando-se num controle moderado da oferta de ensino privado que atenda à demanda não satisfeita pelas instituições apoiadas pelo Estado, bem como em mecanismos que estimulem a competição entre instituições. Na resultante do processo de cortes de gastos públicos e de estímulo à diversificação das fontes de financiamento, em meados da década, menos de $50 \%$ da receita anual das universidades apoiadas pelo Estado provinha de fontes que não implicavam competição por recursos. Numa década dobrou a matrícula no ensino superior, os gastos públicos caíram pela metade e uma parcela de instituições com baixa qualidade no ensino tornou-se parte integrante do sistema. Com efeito, como indica o autor, nas instituições privadas dominam professores horistas e parcos recursos em matéria de bibliotecas e de computação, quando comparadas com as universidades públicas. Menos de $7 \%$ dos alunos que se situam no quintil superior dos resultados dos testes acima aludidos ingressam numa universidade privada; entre os candidatos que escolhem uma universidade privada, três entre quatro dirigem-se para as instituições de melhor qualidade e mais alto prestígio. Além disso, como informam Sanyal e Martín (op. cit.), deteriorou-se a relação entre alunos que se graduam e alunos novos, produzindo elevados custos para um estudante formado.

\section{Equador}

No Equador, a tendência do financiamento segue em direção semelhante à chilena, pois as universidades "tradicionais" 9 vêm buscando fontes alternativas às que prevaleciam até recentemente. $\bigcirc$ financiamento das tradicionais públicas provinha de verbas do governo porém algumas particulares tradicionais, como as católicas de Quito e de Guaiaquil, tinham seus orçamentos cobertos em até $65 \%$ por recursos oriundos do Estado nos anos iniciais da década de 90. A principal fonte alternativa é a cobrança de anuidades, o que poderá "afastar alguns estudantes da universidade de sua escolha e talvez do acesso ao ensino superior", conforme nota Jameson (1997, p.276). A segunda maior fonte tem sido a venda de serviços para o setor privado e público; algumas instituições particulares vêm explorando com êxito a obtenção de doações, mas parece pouco provável que esse caminho possa ser seguido com êxito pela maioria delas. A fundação nacional de pesquisa apóia

9. Estas compreendem as criadas desde o século passado até meados dos anos 80, públicas e particulares, predominando a matrícula em públicas (85\%). 
projetos de investigação em certos departamentos de universidades. $\bigcirc$ apoio do governo central às universidades tradicionais concedia-lhes estabilidade quanto a recursos, autonomia quanto a receitas e quanto a uso das verbas, mas todas vêm buscando novas fontes de financiamento pois a parcela dos recursos públicos aplicados no ensino superior vem caindo em termos reais ${ }^{10}$.

As novas universidades particulares, criadas a partir de meados dos anos 80, desde seu início vêm sendo em geral financiadas inteiramente por recursos privados e nos últimos anos têm absorvido crescentes parcelas da matrícula que antes situavam-se nas universidades tradicionais. Isso tem resultado sobretudo na oferta de cursos de menor custo nas áreas de Administração e Ciências Sociais/Humanidades e que atraem grandes parcelas dos candidatos ao ensino superior, em virtude das menores anuidades cobradas; há inclusive casos de redução dos preços cobrados. No entanto, Jameson (op. cit.) indica que aparentemente a elevada elasticidade de demanda em relação ao preço (anuidades) parece ter alcançado seus limites.

Entende-se que tal conclusão, ainda que provisória, tem relevante implicação. Se na primeira metade dos anos 90 a expansão das vagas nas novas universidades privadas vinha absorvendo crescentes parcelas dos que ingressavam no ensino superior, enquanto permanecia virtualmente estagnada a matrícula nas universidades tradicionais, na segunda metade da década teria sido atingido o limite da capacidade de custeio do ensino superior por parte dos alunos ou de suas famílias. Isso significaria que a retração do Estado no financiamento do ensino superior, em especial no que se refere às tradicionais universidades públicas, que correspondem a mais da metade do total da matrícula nesse nível de ensino no país, estaria representando um freio à expansão do sistema.

México

No México, governos recentes têm buscado implementar políticas de regulação do sistema de ensino superior, de avaliação de instituições, de diversificação de fontes de receita e de diferenciação salarial no setor público, bem como de aproximação das universidades com o setor produtivo da economia. As iniciativas de criar um sistema de avaliação em 1993 foram prejudicadas pela crise econômica (Sanyal, Martín, 1997) e hoje ainda não estão plenamente implantadas (Durham, op. cit.). $\bigcirc$ Estado é responsável por mais de $90 \%$ dos gastos de funcionamento das universidades e o ensino privado tem dimensões relativamente reduzidas, da ordem de $20 \%$ das matrículas. A redução do financiamento governamental por aluno tem levado as universidades públicas a aumentar as taxas de

10. Em meados dos anos 90 os gastos por aluno nesse nível de ensino representavam apenas $40 \%$ de seus valores reais em 1980. Em 1993 o país gastava US\$360 por aluno, muito abaixo da média de US\$648 da América Latina em 1989 (e esta equivale a apenas 20\% da média mundial de US\$3.078, segundo dados de Reimers, apud Jameson, op. cit.). 
matrícula, os preços dos serviços cobrados dos estudantes e do público em geral, o que não tem superado o problema do déficit crônico em que vivem muitas instituiç̧ões.

$\bigcirc$ financiamento das universidades públicas é feito mediante repasses de montantes globais pelo governo a cada ano, cobrindo ensino e pesquisa (esta conta também com o apoio do Conselho Nacional de Ciência e Tecnologia). A sistemática de aportes globais aumentou a autonomia das instituições, porém em grau modesto, pois assim como ocorre na Argentina os recursos para pessoal consomem elevada parcela dos orçamentos (Fanelli, op. cit.). Os recursos são alocados por fórmulas que levam em conta o número de alunos e privilegiam o quadro docente, sendo que esta segunda dimensão, conforme alguns, tem incentivado a expansão do número de professores; entre 199| e 1994 o professorado cresceu mais do que a matrícula (Kent et al., 1997, apud García de Fanelli, op. cit.). Existe alguma diferenciação salarial no setor público, pois desde meados dos anos 80 foi implantado um sistema de bolsas para pesquisadores com elevada produtividade e, na virada da década, um sistema de estímulo ao desempenho acadêmico, administrado pelas próprias universidades, alcançando cerca de $30 \%$ do pessoal docente.

As inovações que vêm sendo introduzidas no financiamento situariam o ensino superior do México numa fase de transição (Barriga et al., 1997). Baseado em um modelo incremental de financiamento, com alocação de recursos por meio de fórmulas, o sistema estaria transitando para um modelo com diversificação de fontes de financiamento e de procedimentos seletivos de alocação de recursos, como os atribuídos por um fundo de

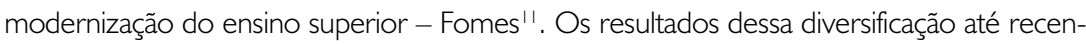
temente teriam sido modestos, considerando-se que dos gastos totais das instituições de ensino superior as fontes alternativas responderiam por valores entre 5\% e 15\%.

\section{UNIVERSIDADE E DIVERSIFICAÇÃO DE FONTES DE FINANCIAMENTO}

No debate acerca da diversificação de fontes de financiamento, as alternativas freqüentemente sugeridas se referem à prestação de serviços por parte das universidades aos mais diversos setores da sociedade civil e política, tais como sindicatos, empresas, organizações não governamentais e governos, especialmente no campo dos programas de treinamento e atualização profissional. $\bigcirc$ conhecimento acumulado e produzido nas instituições de ensino superior pode, com proveito mútuo, ser mais amplamente utilizado pela sociedade em seu conjunto, desde que preservadas as missões básicas das universidades e demais instituições. No entanto, a evidência disponível sugere que essas fontes alternativas sempre terão relevância limitada, sendo portanto essencial a forte participação do Estado no financiamento da universidade pública.

As relações entre universidade e setor produtivo são um caso particular da aproxi-

I1. Ver a discussão em Kent e De Vries (1994). 
mação entre a universidade e a sociedade maior. Podem ser vistas sob a perspectiva da busca de fontes alternativas de financiamento, mas elas têm características próprias que lhes são inerentes.

Na experiência européia, os governos têm facilitado a colaboração entre universidade e indústria. Em vários países vêm sendo implementados programas de financiamento ou estabelecidos estímulos fiscais para projetos conjuntos de pesquisa aplicada, de pesquisa e desenvolvimento de tecnologias (que incluem a criação de empresas usando as tecnologias geradas pelos projetos). Mesmo na Europa Ocidental, apesar dos esforços envidados, as relações entre universidade e indústria ainda não alcançaram uma adequada institucionalização (Emin, Martín, 1996).

Apesar da limitação de ordem institucional, a evidência disponível para países da OCDE aponta para um crescente aporte de recursos da indústria para o financiamento da pesquisa universitária, inclusive em decorrência de políticas governamentais. Por outro lado, o otimismo que por vezes desperta tal crescimento deve ser visto à luz do significado dos números. Como aponta Velho (1999), do que gastam as empresas em pesquisa e desenvolvimento - P\&D - industrial naqueles países, é efetivamente pequena a fração alocada para investigações acadêmicas, pois ela não excede a aproximadamente $1 \%$. Tudo indica que as universidades não são nem serão substitutas para os departamentos de P\&D das grandes empresas ${ }^{12}$.

A autora registra também que como parte da busca de novos mercados e da globalização de suas operações, companhias têm progressivamente deslocado suas atividades de P\&D para fora de suas sedes. Em anos recentes diversas empresas químicas e farmacêuticas européias, por exemplo, criaram laboratórios nos Estados Unidos e lá firmaram contratos com universidades norte-americanas a fim de se situarem mais próximas - do ponto de vista geográfico - de relevantes fontes de geração de conhecimento novo em biotecnologia. Anota ainda que as empresas geralmente buscam parcerias com instituições e grupos de investigação de elevada qualidade científica, o que requer o fortalecimento da pesquisa básica, porém ilustra com grande nitidez a limitação do crescimento das relações entre universidade e indústria como uma fonte alternativa de financiamento. $\bigcirc$ êxito da intensificação de tais relações, além de outras limitações adiante discutidas, estaria reservado a relativamente poucas instituições ou departamentos.

Estudo conduzido no Brasil indicou que as tecnologias mais avançadas vêm embutidas nos produtos e serviços vendidos pelas empresas cujas matrizes estão fora do país e, além disso, as empresas nacionais freqüentemente preferem importar tecnologia. Assim, é muito pequena a demanda de projetos de $P \& D$ por parte das empresas. Embora nas três

12. A autora também chama a atenção para a enorme diversidade que existe entre países e num mesmo país. Se no Reino Unido a contribuição da indústria para o orçamento da pesquisa acadêmica em geral variou em torno de I I\% no período 1987-92, em instituições de elevado prestígio como o University College de Londres, o Imperial College de Oxford e Cambridge ela variou entre I5\% e 20\%; na Universidade de Harvard alcançou 25\%. 
universidades estudadas, todas de elevado prestígio acadêmico, tenham sido observados diversos projetos consorciados de genuína pesquisa tecnológica, verificou-se que a maioria do envolvimento da universidade com o setor produtivo vem se restringindo a atividades de assistência técnico-científica a empresas (Velho, 1996).

Na América Latina, vários projetos vêm sendo levados a cabo com o intuito de aproximar universidades e empresas, como ocorre na Argentina, Brasil, Chile e Uruguai, seja por iniciativa daquelas, seja por estímulo de políticas públicas. Ainda não há suficiente evidência sistematizada que permita avaliá-las em seu conjunto. De todo modo, como indica L. Velho (op. cit.), tais políticas - que foram concebidas e implementadas à luz das adotadas em países industrializados - não podem ignorar o contexto diverso em que são concebidas e implementadas nem as diferenças de comportamento entre os atores envolvidos - universidades, empresas e governos. Faltam estudos que identifiquem, nos países da região, os setores e tecnologias que mais poderiam beneficiar-se de projetos de P\&D locais e que estariam voltados principalmente para a indústria. A hipótese da autora, no entanto, é de que nos anos vindouros a contribuição dos sistemas de P\&D desses residiria mais na solução de problemas sociais do que na oferta de respostas a demandas da indústria, as quais vêm sendo tidas como potenciais mas, de fato, não se têm manifestado.

O cenário esboçado acerca das relações entre universidades e indústria tem claras implicações para a busca de fontes alternativas de recursos por parte daquelas. A primeira implicação é a de que tais fontes serão sempre de pequeno volume, captadas por algumas poucas instituições e, portanto, não podem ser vistas como substitutas da presença do Estado no financiamento da universidade. A segunda decorre da hipótese relativa ao destino dos sistemas de P\&D nos anos vindouros, na região. Se seu principal papel for o de contribuir para a solução de problemas sociais, o Estado certamente será o principal parceiro dos contratos que firmarão as universidades para levar a termo essa tarefa.

\section{TRÊS MODELOS DE FINANCIAMENTO: AS DEFICIÊNCIAS E UMA PERSPECTIVA}

Nesta seção discutem-se três modelos de financiamento - inercial, contratos de gestão e fórmulas - considerando sua concepção e, também, sua aplicação a países da América Latina. $\bigcirc$ tratamento desses modelos no plano conceitual é bem mais fácil do que a discussão em casos concretos, de países da região ou de quaisquer outras nações. Como argutamente observou Sheehan (apud Amaral, 1998, p.26), as comparações de mecanismos de financiamento empregados em diferentes países são de interpretação muito difícil, pois cada sistema de ensino deve ser entendido "no contexto que inclui temas como políticas de ingresso, situação legal das instituições de ensino superior e seu quadro de pessoal, leis nacionais, etc.". Ciente destas limitações, pretende-se argüir contra determinados modelos e a favor de um deles. 
Os modelos de financiamento inercial padecem de conhecidas limitações. Uma delas, talvez a maior, é a falta de estímulo à melhoria da qualidade do ensino, da pesquisa e da extensão, e do aumento da eficiência no uso dos recursos públicos. Ora, se o melhor emprego possível das verbas públicas é um dever ético-político de qualquer instituição, tal dever adquire importância renovada no caso das universidades, especialmente quando são públicas.

Mas a larga difusão do financiamento inercial para as universidades públicas na região parece estar associada, de um lado, ao uso de controles burocráticos-formais por parte do Estado sobre as instituições e, de outro, à limitada autonomia de gestão que de fato têm as universidades. Os orçamentos inerciais serviriam assim como um amortecedor utilizado pelas instituições para reduzir os ímpetos de tais controles e preservar sua autonomia. Esta, se no âmbito acadêmico geralmente pode vicejar, no âmbito da gestão vê-se muito limitada por normas estritas que vigoram para o serviço público e também se aplicam às universidades, incluindo-se, entre outras, as que se referem à contratação e à remuneração de pessoal e aos tipos de despesas que podem ser efetuadas com os recursos transferidos pelo Estado. Este, sem outras formas de controle que não sejam as burocráticos-formais, insiste nelas como tentativa de exercer seu papel de supervisão sobre as instituições.

Tolhidas pelas já aludidas e rígidas normas do serviço público, freqüentemente recebendo recursos que são transferidos com itens de despesas especificados minuciosamente, não dispõem as universidades públicas de condições para atuar com eficiência. As amarras a que estão submetidas, aliadas às práticas do orçamento inercial, tampouco contribuem para que sejam adotadas iniciativas para a melhoria da qualidade do ensino, da pesquisa e da extensão. Ao contrário, quanto mais do anterior, melhor, pois menos difícil torna-se justificar pleitos de aumentos de recursos no modelo de financiamento incremental. Em suma, tal modelo não admite aprimoramento, necessitando completa reformulação a fim de que as universidades públicas possam adequadamente cumprir as tarefas que lhes cabem.

Financiamento por contratos de gestão

No extremo oposto do modelo de financiamento inercial estão os contratos de gestão ou contratos com cláusulas de condicionalidade. Pautam-se eles pelo princípio de que o Estado deve abandonar o exercício de controles diretos sobre o ensino superior, passando a utilizar os recursos públicos para dirigi-lo e valendo-se mais de incentivos e instrumentos orientados para (e pelo) o mercado. Os contratos de gestão atenderiam a esse novo papel do Estado e à pretendida orientação para o mercado. Firmados sobretudo 
entre governo e universidade, os contratos definem objetivos e metas para os quais o financiamento será concedido. $\bigcirc$ modelo tem sido empregado em alguns países europeus da OCDE. A fim de analisar sua pertinência é conveniente entender a universidade como organização especializada, definida pela articulação dinâmica de duas dimensões, a disciplinar e a empresarial, propostas por Cox e Courard (1990) a partir de conceitos desenvolvidos na obra de Clark.

A dimensão disciplinar das universidades está voltada para a descoberta e para a difusão do conhecimento, que continuamente geram desordem no sentido acadêmico do termo. Essa desordem está associada à liberdade acadêmica necessária para a reflexão crítica, para a geração de conhecimento novo. $\bigcirc$ avanço da dimensão disciplinar, por suas próprias características, só pode ter êxito se gerido pela autoridade acadêmica, implicando uma gestão mediante órgãos colegiados ou acadêmicos. $\bigcirc$ poder está dado pelo domínio do conhecimento, pelo reconhecimento acadêmico, pela competência na busca de novos conhecimentos. Já a dimensão empresarial orienta-se para a coordenação no sentido da produção da ordem, do ponto de vista administrativo da instituição. Ela está associada a uma gestão de corte burocrático, lidando com recursos limitados, para fins múltiplos e competitivos. Nessa gestão prevalece um tipo de autoridade geralmente delegada e legitimada pelos docentes e/ou pelo Estado, porém de certa forma análoga à das empresas do setor privado, na qual busca-se o melhor emprego dos escassos recursos disponíveis.

As universidades, como instituições de produção e difusão do saber, precisam apoiarse no primeiro tipo de autoridade e de gestão para atingir suas finalidades. Como instituições complexas que são, também não podem prescindir do segundo tipo de autoridade e de gestão. A convivência desses estilos conflitantes entre si é da natureza da universidade moderna. Se o primeiro exclui o segundo, a instituição não sobrevive como organização complexa. Se o segundo superpõe-se ao primeiro, a instituição abdica de sua função propriamente universitária, como instância privilegiada de difusão e produção de conhecimento.

Os contratos de gestão como forma básica de financiamento da universidade, pretendendo fazê-la responder ao mercado, alteram profundamente a convivência entre os dois estilos de gestão. Na verdade, a forte influência do financiamento via contrato com governos (ou empresas) tende a produzir dois efeitos quanto ao papel desses. Primeiro, eles tendem a tornar-se virtuais substitutos do gestor de estilo empresarial da universidade; segundo, esses novos gestores virtuais tendem a superpor-se à gestão de corte acadêmico, à qual deveriam estar subordinados. A universidade estaria assim a caminho de transformar-se num empreendimento igual a outro qualquer, perdendo sua especificidade como instituição de produção e difusão do saber.

A experiência européia é ilustrativa a esse respeito. Nos diversos países em que esse modelo de financiamento foi implantado, os contratos geralmente buscavam tornar as universidades mais flexíveis em suas respostas às prioridades dos governos. A implantação 
do novo modelo de financiamento geralmente esteve associada a limitações no crescimento dos fundos públicos destinados ao ensino superior e a um aumento do controle sobre seu uso e destinação. Sua principal e nefasta conseqüência tem sido a de permitir que se altere, indevidamente, a natureza da instituição universitária. Baseados no princípio de que as universidades devem responder aos sinais do mercado, como apontam Neave e Van Vught (1991, p. 245), os contratos com cláusulas de condicionalidade consistem "no mais poderoso recurso do governo para alterar a ética da universidade, afastando-a do seu papel de uma instituição a serviço da sociedade e transformando-a, para todos os fins e propósitos, num instrumento a serviço de empreendimentos do governo".

Financiamento por fórmulas

modelo de contratos de gestão para o financiamento básico das universidades certamente não parece adequado, como mostra a experiência. Ele pode ser útil caso tenha um caráter marginal ao financiamento básico das universidades públicas, por exemplo. Nesse caso funcionaria como sinalização acerca das prioridades governamentais e das demandas do mercado, que seriam então processadas no âmbito interno das instituições, segundo os critérios acadêmicos que preservam sua especificidade.

Há alguma semelhança entre o modelo de financiamento público por fórmulas com o dos contratos de gestão. Com efeito, as fórmulas que definem quanto irá receber cada instituição, dado um montante fixo de recursos para todas, em certa medida podem refletir - e em geral refletem - objetivos da política pública para o ensino superior de um determinado governo - e aí reside uma semelhança entre ambos. Mas tal semelhança é mais formal do que real.

Pois entre eles há uma diferença fundamental. Enquanto os contratos com cláusula de condicionalidade baseiam-se em controles exercidos sobre os resultados ou produtos as metas a serem alcançadas -, os modelos com fórmulas concentram-se em indicadores de processo, isto é, de potencial para o bom desempenho, deixando amplos graus de liberdade às universidades para que escolham os produtos que desejam obter - numa palavra, para que exerçam sua autonomia. Como lembram Neave e Van Vught (op. cit., p. 252-53), os controles sobre produtos são substitutos precários dos controles sobre processos. Além disso, o exercício da autonomia pressupõe a subordinação dos resultados aos processos. Mas estratégias de controle governamental sobre os produtos invertem os termos da equação. $\bigcirc$ perigo dessas estratégias, como indicam os autores, é que diante das pressões para produzir mais graduados, publicar mais artigos e registrar mais patentes as instituições façam o que lhes é cobrado; seguindo por este caminho a academia ver-seá, quer queira quer não queira, "progressivamente rebaixada para o 'status de uma fábrica de conhecimentos' - impotente para resistir ao oportunismo político ou aos objetivos de curto prazo estabelecidos pelos governos". 
financiamento por fórmulas, que vem sendo adotado na Argentina, Brasil e México para as universidades públicas, não padece dos equívocos subjacentes ao financiamento por contratos com cláusulas de condicionalidade. Mas pode prover incentivos para a melhoria do desempenho, seja do ponto de vista da eficiência interna, seja na ótica do atendimento a demandas sociais, ao mesmo tempo que preserva amplos graus de autonomia para as universidades.

As experiências da Argentina e a do Brasil a este respeito, nas quais as fórmulas são inicialmente aplicadas a pequena parcela do orçamento, parecem ser adequadas na medida em que permitem às instituições gradualmente se ajustarem ao novo modelo. Uma questão de grande importância nesse modelo é a parcela dos recursos que serão distribuídos mediante fórmulas. Na Argentina, como já se anotou, no ano inicial de aplicação das fórmulas elas apenas abrangeram cerca de $1 \%$ do orçamento das instituições. No Brasil, como se viu anteriormente, a fórmula utilizada inclui um componente de necessidades e outro de desempenho. Este inicialmente tem pequena ponderação, que cresce ao longo dos anos. No caso brasileiro a fórmula foi negociada entre as universidades federais e o governo ${ }^{13}$; por ocasião dessas negociações alguns reitores, sobretudo os de universidades maiores ou academicamente mais consolidadas, argüiram no sentido de que a parcela de recursos alocados mediante desempenho fosse maior do que aquela que finalmente veio a ser adotada.

A introdução do modelo de financiamento por fórmulas freqüentemente vem acompanhada de outras inovações quanto à autonomia e às práticas de gestão financeira. De fato, os potenciais efeitos na melhoria do desempenho das instituições, os quais espera-se que decorram da introdução do novo modelo, podem estiolar-se nas rígidas normas que regem as tradicionais práticas de gestão na maioria das universidades da América Latina.

Na Argentina e no México, o novo modelo veio acompanhado de transferências globais para as universidades públicas, flexibilizando a gestão financeira. No Brasil, a adoção desses tipos de transferências ainda aguarda renovada discussão e tramitação de um projeto de autonomia das universidades federais mediante emenda à Constituição Federal. No Chile, a drástica redução de recursos públicos para as universidades públicas, que as obrigou a buscar fontes alternativas de financiamento, não foi acompanhada de alteração equivalente nas normas que vigiam quanto à gestão e contratação de pessoal; como nota Salmi (1997, p. 813), a Universidade do Chile, pública, hoje enfrenta o "paradoxo de competir com a Universidade Católica, sem gozar das facilidades de gestão de uma universidade privada, enquanto que a Católica continua a beneficiar-se de subsídios do governo".

$\mathrm{Na}$ verdade, o pleno aproveitamento do potencial dos modelos de fórmulas em

13. No caso brasileiro, por exemplo, uma fórmula foi originalmente elaborada pela Associação Nacional de Dirigentes de Instituições Federais de Ensino Superior - Andifes, negociada com o Ministério da Educação e transformada em decreto presidencial em 1994. 
países da região requer a realização de outras mudanças nas instituições e na relação destas com o Estado. Toda e qualquer mudança nesse campo, inclusive a simples definição das variáveis que integrarão um modelo de fórmula, têm maiores chances de eficácia quando estabelecidas mediante negociações que envolvam, entre outros atores sociais, as universidades e os governos. Quanto maior a envergadura das mudanças, mais sua eficácia dependerá da consecução de pactos entre o Estado - nele incluídos os partidos políticos -, a comunidade acadêmica e demais setores sociais interessados.

Autonomia e prestação de contas (accountability)

A substituição do modelo de financiamento por outro mais adequado requer também que as universidades venham a gozar de efetiva autonomia, inclusive autonomia de gestão, e sobretudo de gestão financeira. A contrapartida dessa autonomia é a prestação de contas à sociedade. E a melhor forma de prestação de contas à sociedade é a realização de avaliações cujos resultados sejam publicamente divulgados.

A prestação de contas é indispensável porque é um dever ético-político de toda e qualquer instituição que ofereça um serviço social à população. Mas é especialmente importante no caso das instituições públicas de ensino superior e das demais que recebam recursos do Estado; no caso das primeiras, seria a contrapartida do uso autônomo desses recursos; no caso das segundas, seria a contrapartida do recebimento dessas verbas.

Mas avaliação costuma ser sinônimo de resistência dos entes ou indivíduos avaliados. Exemplo ilustrativo é a experiência brasileira com os Exames Nacionais de Cursos que começaram a ser implantados em 1995. A estes exames deveriam submeter-se todos os concluintes de graduação em Administração, Direito e Engenharia Civil, sob pena de não receberem seus diplomas ${ }^{14}$. Os resultados dos exames não estavam conectados ao financiamento mas havia temores de que isso pudesse vir a ocorrer. As principais resistências à realização dos exames foram registradas em universidades públicas, com destaque para os veementes protestos da entidade nacional dos estudantes de nível superior. Em várias instituições houve notáveis ausências de alunos na aplicação das provas. Ao longo dos anos seguintes ampliou-se o âmbito dos exames, que em 1998 abrangeram dez cursos ${ }^{15}$, minguando as ausências de alunos. Os resultados dos exames, a cada ano publicamente divulgados por instituição - mas não por estudante -, comprovaram o que as avaliações da pósgraduação e outras informações não sistematizadas já sugeriam. As instituições públicas, mais preocupadas com questões acadêmicas ou profissionais, têm padrão de formação nitidamente melhor do que as do setor privado, onde interesses comerciais habitualmente têm precedência (excetuando-se algumas instituições do setor).

14. Trata-se dos cursos que em três áreas do conhecimento distintas contam com grande número de alunos no país.

15. Administração, Direito, Engenharia Civil, Engenharia Elétrica, Engenharia Química, Jornalismo, Letras, Matemática, Medicina Veterinária, Odontologia. 
Processos de avaliação de instituições ou de estudantes de nível superior ainda são incipientes na região. A experiência recente de alguns países escandinavos sugeriria que mecanismos de avaliação mais eficazes são os que combinam uma auto-avaliação, realizada pelas próprias instituições, com procedimentos externos, conduzidos por associações profissionais independentes ou órgãos do Estado (Salmi, 1997). A assertiva em princípio é correta porém apenas parcial. Pois ela não indica para que devem as avaliações ser conduzidas.

Auto-avaliações são de fato indispensáveis pois permitem que as instituições possam conhecer melhor suas deficiências e os meios para superá-las. Avaliações externas das instituições, que podem e devem também contar com a participação de pares, servem ao propósito de prestar contas à sociedade quando divulgadas, e ainda são úteis para a busca de melhorias pelas próprias instituições.

Em todos os processos avaliativos, mediação deve ser a palavra-chave que os caracteriza. As avaliações devem cumprir um papel fundamentalmente mediador na busca da superação de deficiências. Portanto, os resultados de avaliações não devem ser concebidos nem utilizados como elementos automaticamente conectados à alocação de recursos públicos pelos governos. Tal uso tende a retirar-lhes legitimidade. Um fraco desempenho de uma instituição pode depender de um complexo de circunstâncias que extravasa sua própria vontade. Além disso, avaliações com caráter essencialmente punitivo não contam com grandes probabilidades de aceitação social.

As chances de êxito estável da avaliação de estudantes e instituições de nível superior na região, indispensáveis para a prestação de contas à sociedade, estão conectadas pelo menos a três dimensões. Uma delas é a ausência de conexões diretas e imediatas dos resultados das avaliações com o financiamento público. Outra é a mediação que tais processos representem para o aprimoramento de suas atividades. Uma terceira é a aceitação dos processos e resultados da avaliação. Não há avaliação ou prestação de contas à sociedade que tenha efetivo e estável êxito sem que os atores sociais envolvidos as considerem úteis e legítimas.

\section{REFERÊNCIAS BIBLIOGRÁFICAS}

AMARAL, N. Gestão financeira de universidades públicas. Brasília: Instituto ANDIFES, Brasília, 1998. mimeo.

El Sistema federal de enseñanza superior brasileño: organización y financiamiento. Educación Superior y Sociedad, v. 7, n. 2, p. 57-80, 1994.

BANCO INTERAMERICANO DE DESENVOLVIMENTO. Higher education in Latin America and the Caribbean: a strategy paper. Washington, D.C.: Social Programs Division, 1998.

BARRIGA, A. D. et al. Financiamiento y gestión de la educación superior en America Latina y Caribe: la educación superior en Siglo XXl; visión de America Latina y Caribe. In: 
CONFERENCIA REGIONAL SOBRE POLITICAS Y ESTRATEGIAS PARA LA TRANSFORMACIÓN DE LA EDUCACIÓN SUPERIOR EN AMERICA LATINA Y CARIBE. Anais. Caracas: CRESALCNNESCO, 1997. T. II, p. 643-706.

BRUNNER, J. J. From State to market coordination: the chilean case. Santiago: Flacso, 1996. mimeo.

CANTO, O. et al. Financiamento da educação superior brasileira: o sistema público federal. Brasília: Instituto ANDIFES, 1998. mimeo.

CARNOY, M., TORRES, C. Structural change and structural adjustment: a case study of Costa Rica. Paris: Bureau for the Coordination of Operational Activities, UNESCO. 1992.

CASTRO, M. M. A Revolução silenciosa: autonomia financeira da USP e UNICAMP. Washington, D.C.: Banco Interamericano de Desenvolvimento, 1995. mimeo.

CEPAL. Notas de la CEPAL, jan., n. 2, Santiago do Chile, 1999.

COX, C., COURARD, H. Autoridad y gobierno en la universidad chilena (I 950-1 989): categorias de análisis y desarollo historico. In: COX, C. (org.). Formas de gobierno en la educación superior. nuevas perspectivas. Santiago, Chile: Flacso, 1990. p. 5I- 107.

CUNHA, L.A. Critérios de avaliação e credenciamento do ensino superior: Brasil e Argentina. In: VELLOSO, J. (org.). CUNHA, L. A., VELHO, L. Ensino superior no MERCOSUL. Rio de Janeiro: UNESCO, Garamond, 1999.

DURHAM, E. Ensino superior na América Latina: tradições e tendências. Novos Estudos CEBRAP, n. 5I, p. 9I-105, jul. 1998.

EASTON, P., KLEES, S. Education and the economy: considering alternative perspectives: Prospects, v. 20, n. 4, p. 413-28, 1990.

EMIN, L., MARTÍN, M. University-industry collaboration: still a difficult process. IIEP Newsletter, v. 14, n. 2, p. I-2, abr./jun. 1996.

FANELLI, A. M. G. Innovaciones en los mecanismos de financiamiento universitario: la experiencia de la Argentina, Chile y México. Buenos Aires: CEDES, 1997. mimeo.

FIORI, J. L. Ajuste, transição e governabilidade: o dilema brasileiro. In: TAVARES, C. M., FIORI, J. L. (Des)Ajuste global e modernização conservadora. São Paulo: Paz e Terra, 1993.

JAMESON, K. Higher education in a vacuum: stress and reform in Ecuador. Higher Education, v. 33, n. 3, p. 265-81, 1997.

KENT, R. Two positions in the international debate about higher education: The World Bank and UNESCO. Washington, 1995. (Texto apresentado na Reunião Anual da Latin American Studies Association, Washington, D.C, 28-30 setembro.) 
KENT, R., DE VRIES, W. Evaluación y financiamiento de la educación superior en México. Universidade Futura, v. 5, n. 15, p. 12-23, outono, 1994.

KENT, R., DE VRIES, W., DIDOU, S., RAMÍREZ, R. El financiamiento público de la educación superior en México: la evolución de los modelos de asignación financiera en una generación. México, 1997. mimeo.

MARQUIS, C. De la evaluación a las reformas en el sistema universitario argentino. Educación Superior y Sociedad, v. 7, n. 2, p. 13-22, 1996.

NARODOWSKY, P. Como se administra y financia el sistema educativo. In: TIRAMONTI, G. et al. (orgs.). Las Transformaciones en diez años de democracia. Buenos Aires: Tesis Grupo Editorial Norma, 1995. p. 207-40.

NEAVE, G., VAN VUGHT, F. Conclusion. In: NEAVE, G., VAN VUGHT, F. (orgs.). Prometheus bound: the changing relationships between government and higher education in western Europe. New York: Pergamon Press, 1991.

NEGRI, B. Financiamento da educação no Brasil. Brasília: INEP/Ministério de Educação e Cultura, 1997. (Textos para discussão, v. I, n. I)

ORGANIZAÇÃO PARA COOPERAÇÃO E DESENVOLVIMENTO ECONÔMICO. Financing higher education: current patterns. Paris, 1990.

PURYEAR, J., BRUNNER, J. Una agenda educacional en America Latina y el Caribe. Universidade Futura, v. 6, n. 18, p. 35-9, verão 1995.

REIMERS, F. Finance of higher education in the 1990's. In: PURYEAR, J.M., BRUNNER, J. J. (orgs.). Education, equity and economic competitiveness in the Americas. Washington, D.C.: Organização dos Estados Americanos, 1995.

SALMI, J. Opciones para reformar el financiamiento de la enseñanza superior: la educación superior en Siglo XXI; visión de América Latina y Caribe. In: CONFERENCIA REGIONAL SOBRE POLITICASY ESTRATEGIAS PARA LATRANSFORMACIÓN DE LAEDUCACIÓN SUPERIOR EN AMERICA LATINA Y CARIBE. Anais. Caracas: CRESALC/UNESCO, 1997. T. II, p. 797-818.

Perspectives on the financing of higher education. Higher Education Policy, n. 5, p. 3-19, 1992.

SANYAL, B., MARTíN, M. Nuevas estrategias para la gestión de finaciamiento en las universidades: experiencias en los países de la OECE y América Latina. La Educación Superior en Siglo XXI; visión de América Latina y Caribe. In: CONFERENCIA REGIONAL SOBRE POLITICAS Y ESTRATEGIAS PARA LA TRANSFORMACIÓN DE LA EDUCACIÓN SUPERIOR EN AMERICA LATINA Y CARIBE. Anais. Caracas: CRESALC/UNESCO, 1997. T. II, p. 819-54. 
SCHWARTZMAN, J. Questões de financiamento nas universidades brasileiras. Belo Horizonte: Universidade Federal de Minas Gerais, 1998. mimeo.

SHEEHAN, J. Modelos para la asignación de fondos públicos entre las universidades. Nuevas Direcciones en el Financiamiento de la Educación Superior. Buenos Aires: Ministerio de la Educación, 1996.

TILAK, J. B. The Privatization of higher education. Prospects, v. 21, n. 2, p. 60-7I, 1991.

UNESCO. Declaração mundial sobre educação superior no século XXI: visão e ação. Piracicaba: Universidade Metodista de Piracicaba, 1998.

Documento de política para el cambio y el desarollo en la educación superior. Paris, 1995.

VELHO, L. Políticas governamentais e motivações para aproximar pesquisa acadêmica e setor produtivo. In: VELLOSO, J. (org.), CUNHA, L. A., VELHO, L. Ensino superior no MERCOSUL. Rio de Janeiro: CAPES; UNESCO; Garamond, 1999.

VELHO, S. Relações universidade-empresa: desvelando mitos. São Paulo: Autores Associados, 1996.

VELLOSO, J. Financiamiento de la educación superior en América Latina y el Caribe: esquema de análisis y propuestas. La Educación Superior en Siglo XXI; visión de América Latina y Caribe. In: CONFERENCIA REGIONAL SOBRE POLITICAS Y ESTRATEGIAS PARA LATRANSFORMACIÓN DE LA EDUCACIÓN SUPERIOR EN AMERICA LATINA Y CARIBE. Anais. Caracas: CRESALCNNESCO, 1997. T. II, p. 863-89.

Higher education in Brazil: trends and recent developments in resource allocation policies. Paris: IIEP/UNESCO, 1994. (Research Report n. 100)

A reforma do financiamento do ensino e a LDB. 1997a. (Apresentado na 20ª Reunião Anual da Associação Nacional de Pós-Graduação e Pesquisa em Educação - ANPEd -, Caxambu, MG)

WORLD BANK. Higher education: the lessons of experience. Washington, D.C.: The World Bank, 1994. 